\title{
ANALYTICAL AFTERTHOUGHTS ON THE ASIAN CRISIS
}

The worst is now past, or so we hope. But what was it all about? How can things have gone so wrong so suddenly? And what should we do to prevent another financial crisis - or if one comes, what should we do to minimize it?

The truth is that nobody really imagined that something like the Asian financial crisis was possible, and even after the fact there is no consensus about why and how it happened. Still, in the last year or so a number of economists seem to have converged on a view about the Asian crisis that might be described as "open economy Bernanke-Gertler". (See, in particular, my own piece "

", and the recent paper of Aghion, Bachetta, and Banerjee (1999)). The idea is this: suppose that, as argued by Bernanke and Gertler (1989), investment is often wealth-constrained - that is, because firms face limits on their leverage, the level of investment is strongly affected by the net worth of their owners. And suppose also that for some reason many firms have substantial debt denominated in foreign currency. Then two nasty possibilities can emerge. First, a loss of confidence by foreign investors can be self-justifying, because capital flight leads to a plunge in the currency, and the balance-sheet effects of this plunge lead to a collapse in domestic investment. Second, the normal response to recession - namely, printing money - becomes ineffective, even counter-productive, because loose money would reinforce the currency depreciation, and thereby worsen the balance-sheet crunch. And hence the Asian crisis: seemingly irrelevant events caused a self-fulfilling loss of confidence, and conventional macroeconomic remedies were not available.

Now I doubt that anybody believes that this is the whole story; but it is the most persuasive model of the crisis that we have. And we should therefore take that model seriously, and ask what it implies for the future - both for reform of the international financial architecture (of course, the first step in such reform is to find out who is responsible for that pompous phrase, and punish him), and for the response to crises if architecture reform fails.

This note begins with a brief statement of a simplified "1997" crisis model; then describes the apparent implications for policy in a crisis; and finally considers what sort of architecture reform might prevent crises in the first place.

\section{A cartoon model of financial crisis}

Ever since the 1960s, the workhorse of open-economy macroeconomics has been the Mundell-Fleming model. In its simplest version, this model consists of three equations. First is an aggregate demand equation relating domestic spending to real income and the interest rate, together with net exports that depend on the real exchange rate:

(1) $y=D(y, i)+N X\left(e P^{*} / P, y\right)$

Second is a money-demand equation:

(2) $M / P=L(y, i)$

Finally, in the simplest version, investors are supposed to be risk-neutral and have static expectations about the exchange rate, implying an interest-arbitrage equation

(3) $i=i^{*}$

In practice, this model is too simple for even the most basic uses; in particular, nobody believes in static expectations about $e$. A better version of (3) would have expectations that $e$ tends to return to some "normal" value, possibly one determined by purchasing power parity. But let us stick with the simplest version for now. 
This setup can be regarded as simultaneously determining output $y$ and the exchange rate $e$. Figure 1 shows how this works. The vertical line AA shows all the points at which, given (2), the domestic and foreign interest rates are equal. Meanwhile, the line GG shows how output is determined given the exchange rate; it is upward-sloping because depreciation increases net exports and therefore stimulates the economy.

To turn this into a model that can yield crises, all we need to do is add a strong open-economy Bernanke-Gertler effect. Suppose, then, that many firms are highly leveraged, that a substantial part of their debt is denominated in foreign currency, and that under some circumstances their investment will be constrained by their balance sheets. Then the aggregate demand equation will have to include a direct dependence of domestic demand on the real exchange rate:

$\left(1^{\prime}\right) y=D\left(y, i, e P^{*} / P\right)+N X\left(e P^{*} / P, y\right)$

How would this dependence work? At very favorable real exchange rates, few firms would be balance-sheet constrained; so at low $e P^{*} / P$ the direct effect of the real exchange rate on aggregate demand would be minor. At very unfavorable real exchange rates, firms with foreign-currency debt would be unable to invest at all, and therefore the direct exchange-rate effect on demand would be trivial at the margin. (The economy would be like Indonesia today: the corporate sector basically bankrupt and unable to invest, but small firms and farmers benefitting at the margin from a weak currency). But in an intermediate range, the effect might be large enough to outweigh the direct effect on export competitiveness, so that over that range depreciation of the currency would be contractionary rather than expansionary.

In short, as pointed out by Aghion et al, we might expect the GG curve to have a backward-bending segment, as in Figure 2; and hence there could be multiple stable equilibria, one with a "normal" exchange rate, one with a hyperdepreciated exchange rate and a bankrupt corporate sector.

And we immediately have our cartoon version of an Asian-style financial crisis. Something - a whiff of political instability, a financial crisis in another country that investors think looks like you, or even deliberate market manipulation by big speculators - causes a sudden large currency depreciation; this depreciation creates havoc with balance sheets; and the economy plunges into the crisis equilibrium.

Of course it is a highly oversimplified story, and needs a great deal of elaboration (which will surely be forthcoming in the years to come). But simplified and simplistic are not the same thing; arguably this story is more sophisticated than the catchphrases and seat-of-the-pants intuition that governed economic policy during the crisis, and still dominate discussions of architecture reform. So let's look at what this miniature model seems to imply for policy in the crisis and after.

\section{Policy in the crisis}

Suppose that, for whatever reason, your economy seems to be heading for the crisis equilibrium. Never mind new financial architecture; right now you live in a structure that seems to be collapsing. What do you, and your friends at the international financial institutions, do?

In practice orthodox attempts at crisis management seem to have involved five types of action; let me discuss each of them in turn with the model as a backdrop.

(i) IMF financial support: The IMF, together with whatever other sources of funds can be mobilized, provides the troubled country with a credit line. What does this do?

The answer, basically, is that it provides the country with additional funds to intervene in the exchange market more dollars to support the baht, won, whatever. Leaving aside monetary policy (treated below), this is a sterilized intervention; so it is an attempt to use sterilized intervention to move the exchange rate away from the 
crisis equilibrium. The trouble with this policy is, of course, immediately apparent: in a world of high and increasing capital mobility, sterilized intervention is a tool of limited effectiveness. It can still work: capital isn't really as mobile as it is sometimes claimed to be, foreign exchange markets in developing countries often remain surprisingly thin, and within limits intervention can work simply because people think it will work. But leaving aside the psychological impact, it is hard to escape the sense that the importance and effectiveness of credit lines to troubled economies has been exaggerated. Calling the IMF the international lender of last resort sounds impressive; calling it, more accurately, the "sterilized intervenor of last resort" probably more accurately conveys the limits of what a few billion dollars can accomplish.

(ii) Rollovers and standstills : Private creditors are gathered together and persuaded, either by moral suasion or by the threat of unilateral moratorium, to maintain or roll over short-term debts, credit lines, etc..

At one level this is similar to IMF lending: by inducing investors who would otherwise have tried to convert domestic currency into dollars not to do so, it in effect acts as a sterilized intervention on behalf of the currency. One might argue that when a standstill is negotiated in conjunction with a credit line, it is doubly effective, because it shuts off not only the demand for dollars that the creditors would have created in the absence of a program, but the additional attempt to convert local currency into dollars that would have happened as a result of the IMF lending itself.

But creditors will object that they are being unfairly singled out: what if they are bullied into maintaining their positions, while at the same time other investors - say, domestic crony capitalists - flee the currency? And they have a point. Indeed, if there is a very large pool of mobile capital, a standstill that freezes only bank loans (or even one that also freezes bondholders) will alter the composition of capital flight but not its volume; the economy can still be plunged into the bad equilibrium regardless.

How real is this concern? The truth is that in the four front-line Asian crisis countries, and in the related speculative attack on Brazil, short-term debt to banks was the dominant source of capital flight. Close consideration of the day-to-day fluctuations of exchange rates in Brazil also suggests that the foreign exchange market there remains surprisingly thin, so that sterilized intervention can have a big effect on the exchange rate - which means that the standstill agreement Brazil finally negotiated with the banks did make a difference. Only in the case of Hong Kong was the main channel of speculative attack something other than bank debt. So perhaps the fungible-capital world in which neither IMF credit lines nor even "burden-sharing" by private creditors makes much difference has not yet arrived. Still, as markets get more sophisticated and integrated, that day is on its way; in the longer run even broad burden-sharing that encompasses bondholders as well as banks will become increasingly ineffective.

(iii) Fiscal policy: The government does something - expansionary or contractionary - with its budget. In the early stages of the crisis the IMF imposed fiscal austerity; currently the recovery is being partly driven by deficit spending.

It is clear from Figure 2 that the application of fiscal austerity does not in any objective way help prevent or cure an Asian-style crisis. After all, fiscal contraction shifts GG to the left : if anything, this may eliminate the "good" equilibrium and guarantee that the crisis actually happens. Of course, if fiscal austerity creates market confidence - which is to say that the market has some incorrect model of the situation in which austerity is the right answer - then it could work, because when there are multiple equilibria belief can create its own reality. But then perhaps one should try other confidence-inducing measures that do not objectively push the economy in the wrong direction (advertising campaigns? public penance by the leadership, including televised self-flagellation?)

Fiscal expansion, on the other hand, does work: it shifts GG to the right, and if undertaken on a sufficient scale can rule out the crisis equilibrium. The question is whether countries are able to undertake such expansion on the needed scale. Deficit spending strengthens the yen, just as Mundell-Fleming would predict; but it may not be a usable option for smaller nations that are debtors rather than creditors. 
(iv) Monetary policy : The principal, and much-disputed, tool in IMF stabilizations has been a temporary sharp tightening of monetary policy to support the exchange rate, following by gradual loosening once confidence seems to have been restored.

Somewhat surprisingly, our cartoon model allows a rough rationale for the "IMF recipe". Consider Figure 3 , and imagine that for some reason markets appear to have become convinced that the economy is heading for the crisis equilibrium - a belief that, if unchecked, will become self-fulfilling. One way to prevent this from happening is to drastically tighten monetary policy, shifting the AA curve so far to the left that it becomes like $\mathrm{A}^{\prime} \mathrm{A}^{\prime}$ - that is, far enough to rule out the crisis equilibrium. Once investors have become convinced that the exchange rate is not going to depreciate massively, this monetary contraction can be relaxed.

The problem, of course, is that along the way the economy faces a sharp contraction in real output, with all the social and perhaps political disruption that causes. Also, although I cannot capture it in this miniaturized framework, a large real contraction can itself cause a collapse of investment, putting the economy into a different but equally unpleasant form of low-level trap. (See the discussion of this point in "Balance sheets, the transfer problem, and currency crises").

You could argue, based on the Mexican and Korean experiences, that this strategy - whenever there is a basically arbitrary loss of confidence in an economy, impose a temporary monetary contraction and hence a severe but hopefully short-lived real contraction - works in the end. But you have to admit that it's a hell of a way to run a world economy.

(v) Structural reform : When the crisis occurs, the government is urged to announce and implement major structural reforms such as privatization, cleanup of bad banks, etc..

In the context of our cartoon model, it is hard to see why this is an effective crisis policy. That is not to say that structural reform is a bad thing: all of the crisis countries had (and still have) very unsound economic systems. But if you believe that the crisis itself was mainly a matter of self-fulfilling pessimism, it is hard to see why structural reform should be helpful - unless, the all-purpose answer, it somehow leads to increased confidence.

An aside: in practice, the unusual extension of IMF policy in this crisis to embrace wider issues of economic governance probably hurt rather than helped confidence. On one side, it fed the perception that the problems of the crisis countries were deep and not easily resolved; on the other, it led to struggles over implementation that reinforced the sense that things were out of control.

If this review of the standard options for crisis management seems rather downbeat, it should. The truth is that none of the over-the-counter remedies seems to work very well - although it seems fairly clear that at least for now we should be quicker to prescribe debt standstills and rollovers rather than depending entirely on confidence-building gestures.

What could be done? Well, the obvious answer - you knew this was coming! - is to rule out the bad equilibrium by force majeure, imposing capital controls as a temporary emergency measure during a crisis. Conceptually, this should be viewed as a logical extension of the case for agreements to roll over short-term debt: it simply involves concerted action by a larger class of investors. The main objections to temporary capital controls ought to be practical - the claim that they will disrupt ordinary commerce, or inevitably lead to irresponsible policies on the part of the imposing government. For what it is worth, Malaysia's experience suggests that the practical difficulties are not as large as widely claimed. And the absence of large capital flight when the controls were loosened does indicate that controls can be successfully advertised as temporary measures, and removed when the risk of self-fulfilling pessimism has abated.

An analytical approach to the crisis suggests, then, that when the next crisis comes we ought to try from the start to impose some kind of curfew on capital flight. Perhaps this need only take the form of debt rescheduling 
for now; but the possibility of more comprehensive controls should not be ruled out.

Of course, the best answer would be not to get into a crisis in the first place. What might prevent future crises?

\section{Architecture and all that}

I don't know who came up with the term "international financial architecture". Aside from the perhaps inevitable pompousness, the trouble with this phrase is that it suggests a deliberate, controlled structure that simply does not exist in a world of fluid capital markets and very limited official control. The Bretton Woods system - which basically assumed a world in which private capital movements were of limited significance, and in which the key question was one of setting the rules of the game for government-to-government lending could be regarded as a piece of "architecture". Whatever system or non-system we now impose will be at best a set of guidelines on policy between crises.

Let me put on one side the apple-pie-and-motherhood stuff about transparency, and focus on the two real areas of dispute: what should be done with the exchange rate regime, and what should be done about capital flows.

The exchange rate regime: An odd aspect of the aftermath of the crisis is that some people emerged from it convinced that fixed exchange rates were the villain, and that a floating regime could prevent future crises; while other people found it a compelling demonstration of the importance of strongly fixed regimes, such as currency boards, or even dollarization. The funny thing is that our cartoon model helps suggest why both sides might be right.

The case for a currency board, or even dollarization, can be made by considering whether the IMF recipe of temporary tight money would really be necessary if the exchange rate were completely credible. Suppose that everyone knows that a government will not, under any circumstances, allow the kind of currency depreciation that would lead to a circular process of depreciation and balance-sheet collapse. Then the market will not come to expect the depreciation in the first place, and the crisis will not get started. A truly credible commitment to a fixed exchange rate, in other words, can prevent Asian-type financial crises. And this is true a fortiori of the ultimate version of such a commitment, which is not to have a national currency at all.

The problem, of course, is that there are other risks in the world besides Asian-type crises - garden-variety recessions, massive bank failures, and so on. And a currency board or dollarized system leaves a country with reduced ability to respond to such risks. It would be wrong to make too much of Argentina's current recession; these things happen now and then. But the recession surely does remind us that, contrary to the claims of their enthusiasts, currency boards do not exempt their owners from the ills to which economies that have renounced stabilization policy are prone.

What about floating exchange rates? The main claim of those who advocate them as an "architectural" measure, as opposed to a useful tool of macroeconomic policy, is that the exchange regime itself affects the composition of debt. When a country has a more or less fixed exchange rate, the story goes, companies are going to be tempted to go for the lower interest rates they can get by borrowing in dollars or yen; in so doing they create the backward-bending segment of GG that is key to the possibility of crisis. By having a floating exchange rate, then, a country can discourage foreign-currency-denominated debt, and thereby make itself less vulnerable.

To a trained economist this view immediately sounds fishy: if there is a risk of future devaluation, why are domestic borrowers so willing to take on foreign-currency debt. But maybe there is some exchange rate illusion involved; certainly it is true that countries with quasi-fixed rates have tended to have more dollar debt than those without.

The final question here is why be so indirect about it. If foreign currency debt is a problem, why not discourage it directly rather than depending on exchange volatility to do the job? 
Capital flows: In the light of the cartoon model, four sorts of proposals not normally regarded as similar can be seen as conceptually very related. These are proposals to enhance the ability of the IMF (or perhaps other institutions) to offer credit lines to threatened countries; Feldstein-type proposals for "self-protection" via maintenance of large foreign exchange reserves; proposals for some presumption of private sector involvement, aka burden-sharing, in periods of difficulty; and proposals for Chilean-style restrictions on short-term borrowing. The reason these are all conceptually similar is that they all are, in effect, proposals to undertake sterilized intervention to support the exchange rate when a crisis of confidence is threatened.

This is obvious for the first two policies. Liquidity provided in a crunch, whether via loans from abroad or from the country's own reserves, allows intervention in the exchange market; unless this is also part of a monetary contraction, it is sterilized intervention. But as I pointed out earlier, getting foreign creditors to maintain their short-term loans is also in effect a form of sterilized intervention; and providing incentives for domestic firms not to take on short-term debt in the first place is a more indirect way of doing the same thing.

Will such measures work? It depends, again, on what you think about the effectiveness of sterilized intervention. My general view is that the integration of world capital markets is a bit less dramatic than widely believed, and that sterilized intervention therefore does make a difference. But much though not all such intervention will be offset by other kinds of capital flows, meaning that all of these proposals will (if they are implemented at all) prove disappointing to their proponents - and as capital markets become more sophisticated, they will become ever less effective.

What would work? I have already suggested a possible answer: if the key to the risk of crisis is foreign-currency-denominated debt, then concerned countries should tax or otherwise discourage such debt (as opposed to simply hoping that a floating exchange rate will have the same effect). The point, again, is to eliminate the backward-bending segment of GG, and hence the danger of self-fulfilling financial crisis.

But let me not try too hard to resolve the question of financial architecture reform; it is not exactly a burning issue right now, since it seems very unlikely that anything important will actually happen until the next crisis rolls around. The main point of this analytical note is to suggest a way of thinking about the crisis past - and to argue that policy recommendations for crises future ought to flow from our best analytical shot, not from ideological preconceptions.

\section{REFERENCES}

Aghion, P., Bacchetta, P., and Banerjee, A. (1999), "A simple model of monetary policy and currency crises", mimeo

Bernanke, B. and Gertler, M. (1989), "Agency costs, net worth, and economic fluctuations", American Economic Review 79, 14-31.

Krugman, P. (1999), "Balance sheets, the transfer problem, and financial crises", forthcoming in Robert Flood Festschrift volume. (available as http://web.mit.edu/krugman/www/FLOOD.pdf)

Figure 1 


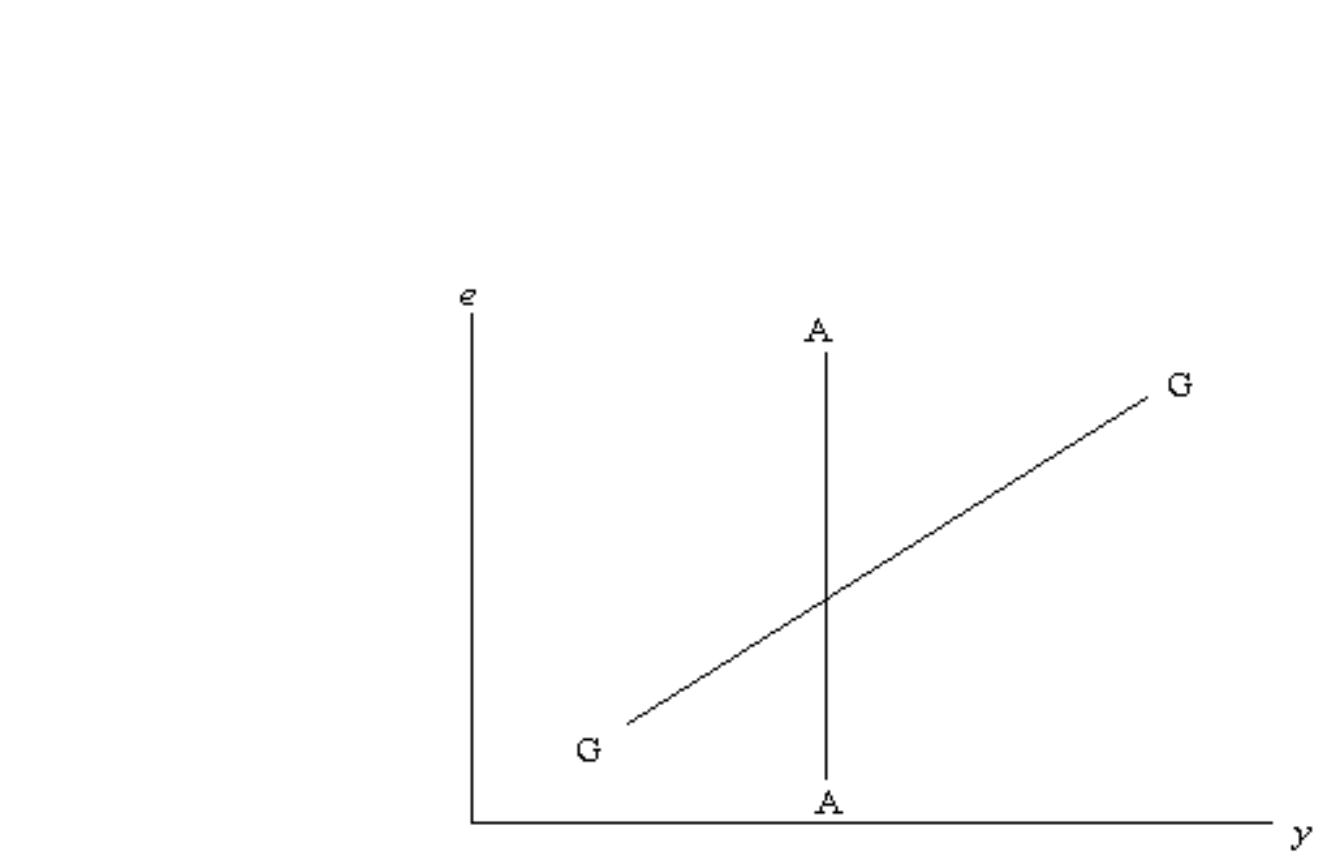

Figure 2

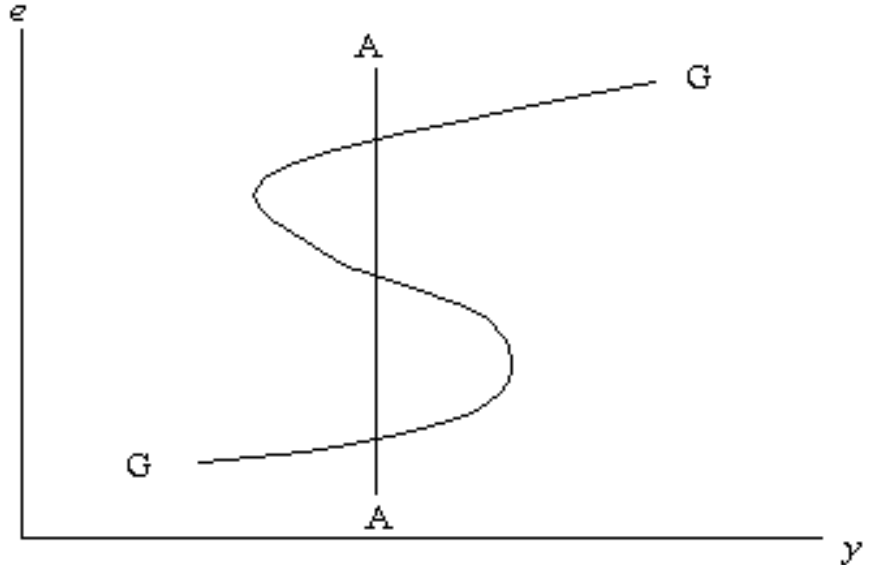

Figure 3

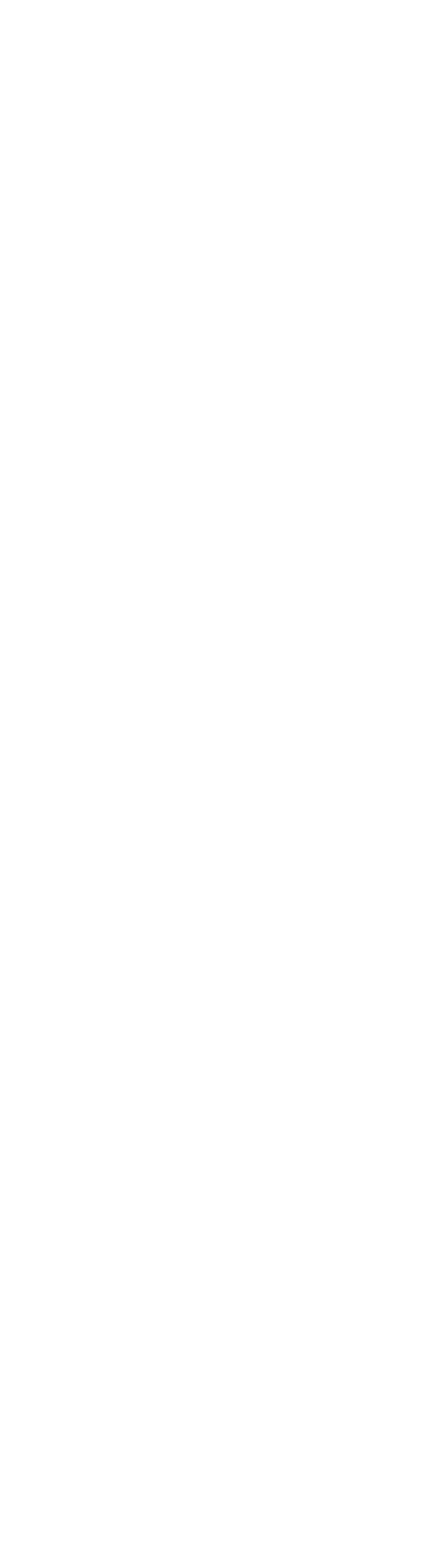

(1) 

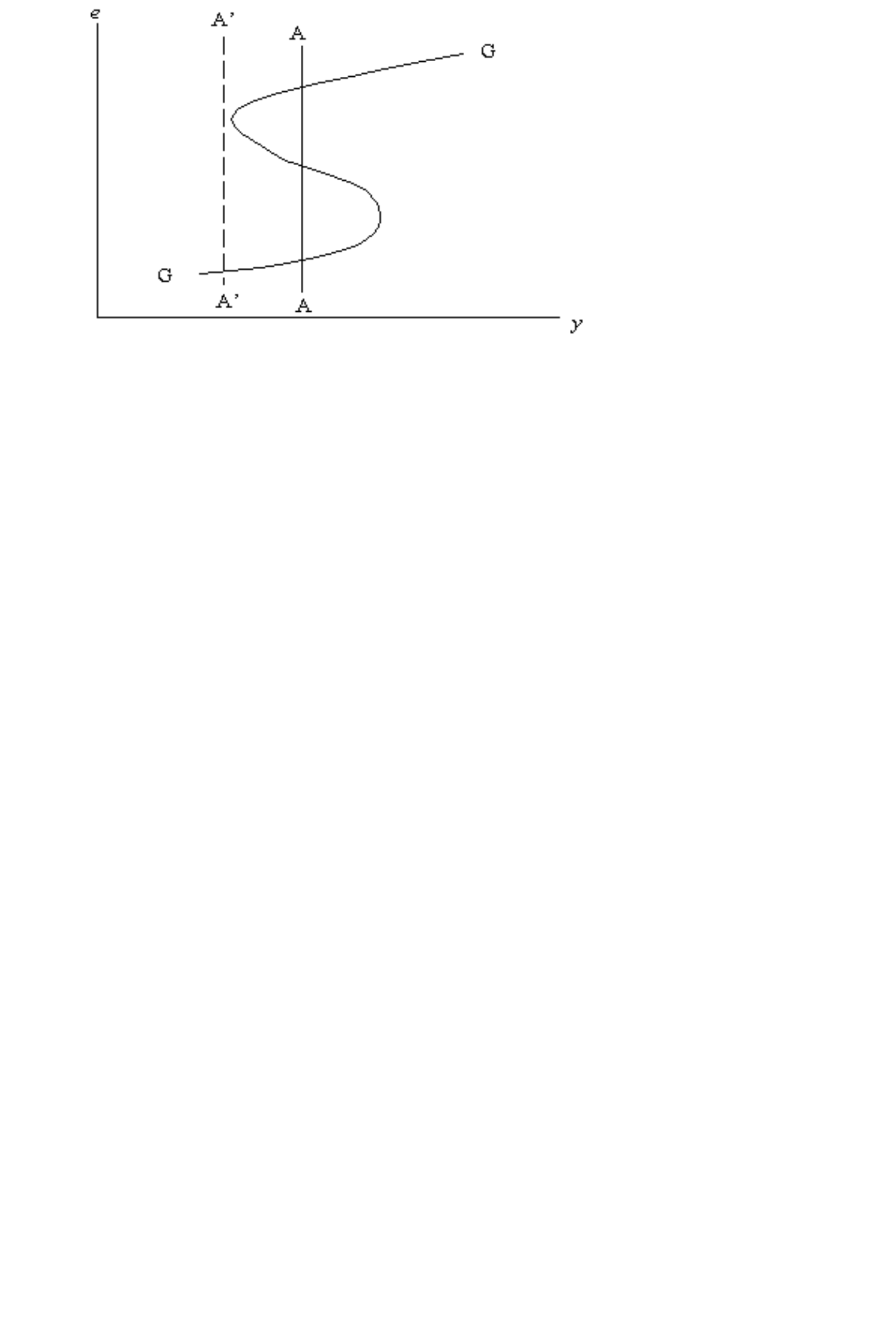